\title{
Chemical Oxygen Demand Analysis of Anaerobic Digester Contents
}

AUTHORS: Colin M. W. Harnadek, Nigel G.H. Guilford, and Dr. Elizabeth A. Edwards

SCHOOL: Department of Chemical Engineering and Applied Chemistry, University of Toronto

\section{Abstract}

An anaerobic digester converts organic materials into biogas and digestate in the absence of oxygen. The organic materials studied in this experiment include fibres (types of paper or cardboard), food waste, and woodchips, which serve as a bulking agent. To analyze digester performance, it is necessary to calculate an accurate mass balance based on the chemical oxygen demand (COD) entering and exiting the system. Digester performance refers to maximum efficiency and biogas yield. The COD of the biogas is known, but that of the feed and the digestate is not. This paper describes a method for measuring the COD of the feed materials and the digestate by creating representative aqueous suspensions of each. The challenges are to ensure that the suspensions are representative of the feed or digestate, and that samples of the suspension extracted for COD analysis are consistent and reproducible.

To obtain an accurate COD measurement of the feed and digestate samples, a specific procedure was developed: each material was processed in a blender with deionized water, creating a pulp from which samples were pipetted during continuous mixing of the suspension. The conducted trials provided COD content values ranging from $1.27-1.59 \mathrm{~g}$ of $\mathrm{COD} / \mathrm{g}$ of dry feed, depending on the fibre. Standard deviations of the COD content ranged from $2.8 \%$ to $12.7 \%$, indicating that the procedure is reliable and the results precise. The measured COD content values allow an accurate mass balance of the digester to be determined, ultimately providing a better understanding of the system as the total digestible material entering the digester will be known. An accurate mass balance can improve the efficiency of the digester in order to produce optimal quantities of biogas. The biogas can be harnessed into energy from otherwise useless waste. Further study in this topic can explore the COD content of wider ranges of organic solids as well as further optimize the procedure in order to provide even more accurate results.

\section{Key Words}

Solid Organic Waste, Anaerobic Digestion, Chemical Oxygen Demand

\section{Background}

Standard COD measurements for solid wastes are not available (1) and prior research on the anaerobic digestion of solid organic waste has mainly looked at digestion of municipal solid waste, animal manure, sewage sludge and food waste (2-4). There are no current methods of determining the COD content of solid organic wastes such as cardboard, paper, or wood chips.

\section{Introduction}

BioZone, of the Department of Chemical Engineering at the University of Toronto is currently conducting analysis on the anaerobic digestion of solid organic waste in research conducted by Ph.D. candidate Nigel Guilford. The digester was designed to digest solid organic waste, to produce biogas (a source of energy), and to produce compost from the digestate recovered at the end of the process. Anaerobic digestion is one of the most viable options for recycling the solid portion of organic waste as it is viable for wide varieties of organic wastes and allows for energy to be harnessed from the produced biogas (5).

The system included solid organics entering and exiting the digester, as well as biogas (mainly carbon dioxide and methane) exiting the digester. The mass balance was determined on a chemical oxygen demand (COD) basis. This method of analyzing the mass balance was efficient because it allowed the solid organic matter, the liquid leachate inside the digester and the biogas to be easily compared. In addition, there is a direct relationship between COD and the volatile solids (VS) of an organic material. The volatile solids of an organic material was measured by igniting a dried sample at $550^{\circ} \mathrm{C}$, and recording the amount of volatile material lost. The measurement of volatile solids is easy and accurate; once the COD content of the solid organic material is known, and the ratio of COD to VS is known, the COD of future solid organics entering and exiting the digester can be determined by testing for the volatile solids instead.

The COD content of the leachate circulating throughout the system was known and the COD content of the biogas produced by the digester could be determined by measuring the methane content using a gas chromatograph equipped with a flame ionization detector (GC-FID). However, the COD content of the solid organic 
material entering and exiting the digester was not known. The solid organic materials analyzed in this paper are mainly fibres and materials that have been recycled. The paucity of research on the COD content of fibre based organic solids is due to the difficulty in accurately measuring this value. In order to test for COD content, the organic material must be in solution, or in a very fine suspension in order to use a spectrophotometer for measurement of COD (6). The challenges present in the creation of this suspension are to ensure that the suspension is representative of the feed or digestate, and that samples of the suspension extracted for COD analysis are consistent and reproducible.

The organic materials that were tested for COD content included fine paper, newsprint, cardboard, boxboard, food waste, wood chips and digestate. However, the procedure outlined in this paper is not limited to these materials. It can be applied to any solid organic material that can be blended into a very fine suspension.

\section{Methodology}

Chemical oxygen demand is a measure of the oxygen required to oxidize all organic material present into water and carbon dioxide, and thus a measure of the amount of organic material within a substance (7). There are multiple methods to test for the COD of a solution or suspension of organic material, including titrimetric and photometric methods (8). The results of this paper were based on a photometric method with the use of potassium dichromate $\left(\mathrm{K}_{2} \mathrm{Cr}_{2} \mathrm{O}_{7}\right)$ as the main oxidant (8).

Potassium dichromate is a strong oxidizing agent in an acidic environment, and the organic material is oxidized by potassium dichromate's hexavalent dichromate ion $\left(\mathrm{Cr}_{2} \mathrm{O}_{7}^{2-}\right)$. The oxidation reduces $\mathrm{Cr}_{2} \mathrm{O}_{7}{ }^{2-}$ to the $\mathrm{Cr}^{3+}$ ion, which is green and absorbs light in the visible spectrum (610 nm wavelength), whereas $\mathrm{Cr}_{2} \mathrm{O}_{7}{ }^{2-}$ does not. In essence, the extent of oxidation dictates the amount of $\mathrm{Cr} 3+$ ion formed, which affects how much light will be absorbed by the sample in the spectrophotometer (8).

$\mathrm{C}_{\mathrm{n}} \mathrm{H}_{\mathrm{a}} \mathrm{O}_{\mathrm{b}} \mathrm{N}_{\mathrm{c}}+\mathrm{dCr}_{2} \mathrm{O}_{7}^{2-}+(8 \mathrm{~d}+\mathrm{c}) \mathrm{H}^{+} \rightarrow \mathrm{nCO}_{2}+\frac{\mathrm{a}+8 \mathrm{~d}-3 \mathrm{c}}{2} \mathrm{H}_{2} \mathrm{O}+\mathrm{cNH}_{4}^{+}+2 \mathrm{dCr}^{3+}$

The spectrophotometer produces measures of absorbance, which are converted into grams per liter of COD using a calibration curve. This value can then be converted into COD ( $\mathrm{g} / \mathrm{g}$ dry feed) by multiplying the COD of the sample $(\mathrm{g} / \mathrm{L})$ by the known suspension concentration $(\mathrm{g} / \mathrm{L})$ :

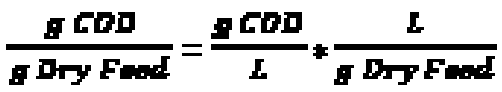

\section{Materials}

To create the suspension of organic matter, a known dry amount of solid organic material was placed in a commercial food blender (Blendtec Wild Side+ Model). To take samples of the suspension and dilute it to the required concentration, a pipette and $15 \mathrm{~mL}$ plastic vial were used. Additionally, $10 \mathrm{~mL}$ glass vials and caps were needed in order to perform the COD test on the diluted suspension. The chemicals added to the diluted organic suspension to test for COD included:

- $3.5 \mathrm{~mL}$ silver sulphate / sulphuric acid solution

$010 \mathrm{~g} / \mathrm{L}$ silver sulphate in concentrated sulphuric acid

- $1.5 \mathrm{~mL}$ potassium dichromate solution

$010 \mathrm{~g} / \mathrm{L}$ potassium dichromate

$033.3 \mathrm{~g} / \mathrm{L}$ mercuric sulphate

$0165 \mathrm{~mL} / \mathrm{L}$ sulphuric acid

In addition to these chemicals, a vortex, reactor $\left(150^{\circ} \mathrm{C}\right)$, and spectrophotometer were required to test for COD. Finally, Microsoft Excel was used to organize the data and to calculate the COD $(\mathrm{g} / \mathrm{g}$ dry feed) from the absorbance values provided by the spectrophotometer.

\section{Procedure}

\section{Procedure for creating all organic solid samples except for wood chips:}

1. Create a very fine suspension of the organic solid in de-ionized water.

a. Add a known amount of dry organic solid to a known amount of de-ionized water in the blender.

b. Blend until the suspension is very fine. At this point in the procedure, the suspension should look "pulp-like".

2. Continuously mix the suspension, such that a small vortex is created at the top of the mixture.

3. Pipette a $10 \mathrm{~mL}$ sample of the suspension into a $10 \mathrm{~mL}$ plastic vial.

a. Cut the pipette tips to prevent plugging by larger par ticles.

4. Dilute the suspension with de-ionized water to $0.3 \mathrm{~g} / \mathrm{L}$.

5. Pipette in triplicate $2.5 \mathrm{~mL}$ samples of the fully diluted suspen sion into $10 \mathrm{~mL}$ glass vials and a single $2.5 \mathrm{ml}$ sample of deionized water to serve as a blank.

A different procedure is used to prepare the wood chip samples because the coarser wood particles will not remain in suspension.

COD values of the particular organic solid are known, the COD/ VS ratio can be determined and volatile solid testing can be used to 
Table 1: COD ( $\mathrm{g} / \mathrm{g}$ dry feed) for Different Solid Organic Material

\begin{tabular}{|c|c|c|c|c|c|c|c|}
\hline & Newspaper & Fine-paper & Cardboard & Boxboard & Food Waste & Digestate & Wood Chips \\
\hline Average & 1.59 & 1.27 & 1.58 & 1.47 & 1.42 & 1.44 & 1.29 \\
\hline Standard Deviation & 0.04 & 0.14 & 0.05 & 0.19 & 0.13 & 0.11 & 0.16 \\
\hline
\end{tabular}

\section{Procedure for creating wood chip samples:}

1. Screen the wood chips, separating the -212 micron particles.

2. Dry the -212 micron particles to remove all moisture.

3. Add known amount of dry -212 micron particles to known amount of de-ionized water.

4. Allowed suspension to soak overnight in de-ionized water, during which time the wood becomes saturated.

5. Continuously mix the suspension, such that a small vortex is created at the top of the mixture.

6. Pipette a $10 \mathrm{~mL}$ sample of the suspension into a $10 \mathrm{~mL}$ plastic vial.

a. Cut the pipette tips to prevent plugging by larger par ticles.

7. Dilute the suspension with de-ionized water to $0.3 \mathrm{~g} / \mathrm{L}$.

8. Pipette triplicate $2.5 \mathrm{~mL}$ samples of the fully diluted suspen sion into $10 \mathrm{~mL}$ glass vials and a single $2.5 \mathrm{ml}$ sample of deionized water to serve as a blank.

\section{Procedure for conducting COD testing on samples:}

1. Add COD chemicals to the organic suspension.

2. Mix the sample with a vortex.

3. Place sample in a $150{ }^{\circ} \mathrm{C}$ reactor for 120 minutes.

4. At the end of the incubation period, test sample in a spectro photometer starting with the water sample to calibrate the de vice.

a. The absorbance values provided by the spectrophotom eter allow for calculation of the COD content of the sus pensions.

\section{Results and Discussion}

The COD content of fine-paper, newsprint, cardboard, boxboard, food waste, wood chips, and digestate was measured. Nine trials were conducted on each of the four fibres, six trials were conducted on wood chips, five trials were conducted on food waste, and four trials were conducted on digestate. The variation of numbers of trials conducted on each material is because the fibres, wood chips, food waste, and digestate COD tests were conducted on separate occasions and time was a limiting factor in how many trials in total could be completed.

Table 1 and Figure 1 show the average COD ( $\mathrm{g} / \mathrm{g}$ dry feed) for each organic solid as well as the standard deviation between results from different trials.

Newspaper and cardboard have the highest COD content. Finepaper has the lowest, as it is hypothesized to contain many inorganic whiteners. Boxboard, wood chips and food waste had the highest standard error values. The high standard error of boxboard is a result of the intrinsic variability of its composition. The variability in the boxboard is because the boxboard material received by Biozone was composed of boxboard from many different sources. The high standard error in the wood chips results may be due to the difficulty in achieving a homogenous suspension despite the use of only fine particles.

Some error is expected in the results because of the difficulty in accurately creating a fine suspension of solid organic waste. Yet the standard errors of the mean of results over all trials is less than 6 $\%$, which shows that the procedure is reliable and replicable. Once determine the COD content of that organic solid in the future.

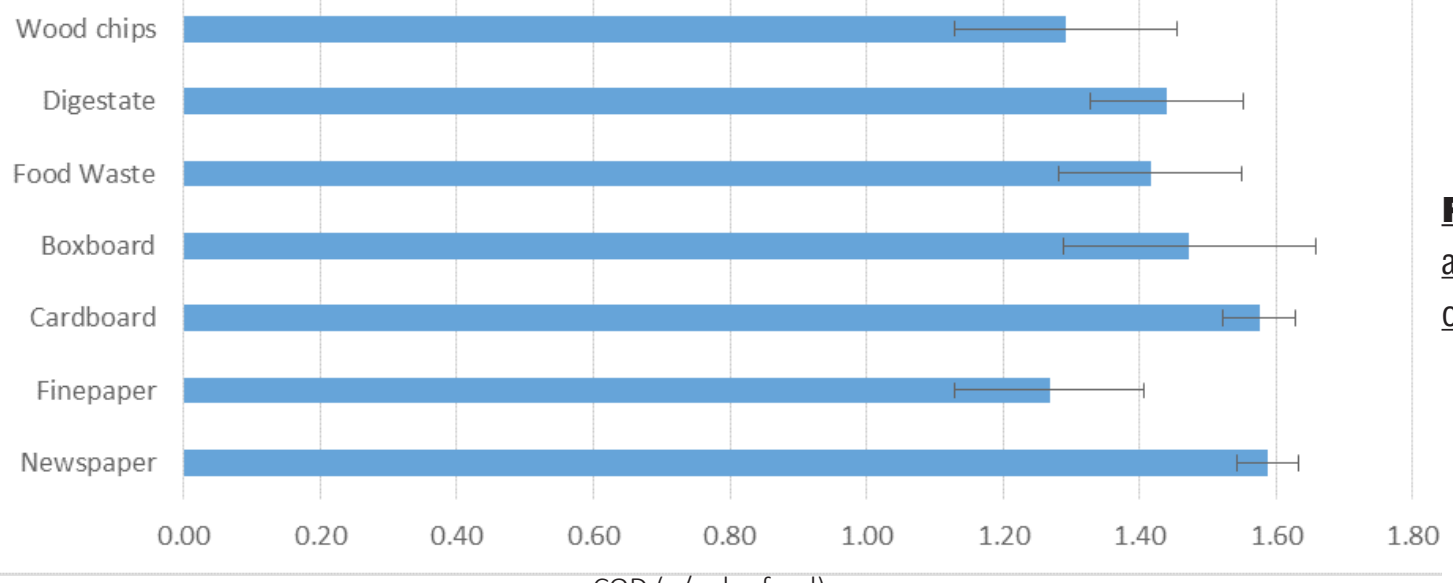

Figure 1: Average COD values and Standard Deviations for organic materials 
There is a direct relationship between the COD and the VS (volatile solids) of an organic solid. It was observed that the percent VS in the finest particles of the woodchips was actually much lower than the percent VS in other size fractions. This was because fine inorganic materials tend to be present in this size fraction. To calculate the COD content of the entire wood sample, the VS content of each size fraction was determined, and used to prorate the COD based on VS content.

\section{Conclusions}

The COD content of organic solids is difficult to determine and the COD content of fibre-based organic solids has not been thoroughly studied. This paper shows that these COD content values are obtainable, and with the use of the procedure outlined, are reliable and reproducible. Using the outlined procedure, COD content values were determined for fine paper, newsprint, cardboard, boxboard, food waste, wood chips and digestate. Future directions for study on the COD content of organic solids will include determining the COD content for wider ranges of solids, as well as refining the process of determining these COD values in order to further optimize the results. This research will allow mass balances of anaerobic digesters containing organic solid wastes to be completed in terms of COD. This will allow for a better understanding of the system and therefore will aid in the optimization of the digester as a whole.

\section{Acknowledgments}

Funding for the project came from NSERC - CRSNG (grant \# 295952701) and from Miller Waste Systems Inc.

The following people provided me with aid during my research:

- Dr. Elizabeth Edwards, Professor, University of Toronto, Department of Chemical Engineering and Applied Science

- Nigel Guildford, Ph.D. student, University of Toronto, Department of Chemical Engineering and Applied Science

- Peter Lee, Masters student, University of Toronto, Department of Chemical Engineering and Applied Science

\section{References}

1. Buffiere P, Frederic S, Marty B, Delgenes J. A comprehensive method for organic matter characterization in solid wastes in view of assessing their anaerobic biodegradability. Water Science \& Technology. 2008;58(9):1783.

2. De Bere L. Anaerobic digestion of solid waste: state-of-the-art. Water Science and Technology. 2000;41(3):283-290.

3. Li Y, Park S, Zhu J. Solid-state anaerobic digestion for methane production from organic waste. Renewable and Sustainable Energy Re views. 2011;15(1):821-826.

4. Monnet F. An Introduction to Anaerobic Digestion of Organic Wastes [Internet]. Biogasmax. 2003 [cited 10 October 2015]

5. Khalid A, Anjum M, Mahmood T, Dawson L. The anaerobic digestion of solid organic waste. Waste Management. 2011;31(8):1737-1744.

6. Boyles W. The Sciences of Chemical Oxygen Demand. 1997.

7. Watershed Protection Plan Development Guidebook. Description of Commonly Considered water Quality Constituents [Internet]. [cited 10 October 2015]

8. Stone J. The Chemistry of Chemical Oxygen Demand [Internet]. envexp. 2015 [cited 10 October 2015].

\section{REVIEW}

\section{by Dr. Penney Gilbert,}

\section{Assistant Professor, Institute of Biomaterials and Biomedical Enginnering, University of Toronto}

Colin's research paper discusses the process of determining the chemical oxygen demand (COD) content of solid organic waste. The paper describes the procedure and materials needed in order to determine the COD content of organic solids in detail. The paper also provides the methodology behind testing for COD content, and a discussion of the results of the trials in the experiment.The introduction and methodology provide an appropriate amount of background information on previous testing for COD of solid organic wastes and how COD tests work. It was also mentioned that prior research on the COD values of the solid organics tested in the paper have not been conducted. The results were concise and differences were discussed. The measurements of dry organic solids used in order to optimize accuracy of the COD measurement with the use of the given procedure could have been discussed. In addition, the number of trials used for some of the solid organic wastes (food waste and digestate) was very small and it should be emphasized that the given COD values for these organic solids have some error present because of the current sample size.Overall it was a good paper that provided the reader with all the required knowledge in order to understand the results and replicate the experiment. 